\title{
Management of head and neck radiation therapy complications
}

\author{
Igor Figueiredo Pereira* and Belmiro Cavalcanti Do Egito Vasconcelos \\ School of Dentistry, University of Pernambuco. Department of Prosthodontics and Bucco-Facial Surgery, Universidade de Pernambuco, Faculdade de Odontologia \\ - Hospital Universitário Oswaldo Cruz. R. Arnóbio Marquês, 310 - Santo Amaro, Recife - PE, 50100-130. Universidade de Pernambuco - PE, Brazil
}

\begin{abstract}
Cancer is considered a public health problem and affects thousands of people around the world. The incidence of head and neck cancer has been increasing and this disease causes serious damage to the patient, mainly due to the location of the lesions.

Treatment consists of surgery, when it is possible, radiotherapy and chemotherapy. This combination has serious consequences for the patient, many complications resulting from this treatment. Surgery can leave irreparable sequelae, radiotherapy causes serious damage not only to cancer cells, but also to healthy cells, which can lead to complications such as: radiation caries, xerostomia, mucositis, candidiasis and osteoradionecrosis. In this review, the main forms of treatment for these outcomes that are so harmful to patients will be addressed, affecting not only the treatment as a whole, but their quality of life.
\end{abstract}

\section{Introduction}

Head and neck cancer (HNC) is used to describe a group of several malignant tumors in the upper part of the aero digestive tract, covering at least 30 diseases, according to the World Health Organization (WHO) [1]. A common site of occurrence is the oral cavity, with more than $40 \%$ of cases. Other common sites for the primary tumor include the pharynx, larynx, nasal cavity and paranasal sinuses. Squamous cell carcinoma being the most prevalent [2].

Patients who are undergoing treatment for head and neck cancer, can be treated through surgery, to remove the tumor, with safety margins, chemotherapy, as an adjuvant and radiotherapy, which damages normal cells, especially those that are less able to repair the damage caused [3]. In the oral cavity, these cells can be from the mucosa, underlying tissues, tooth, periosteum, bone, glands and vessels, resulting in specific radiation complications, of which the following stand out: radiation caries, xerostomia, mucositis, candidiasis and osteoradionecrosis [4].

These patients need specific care, not only after radiotherapy, but before, where an adequacy and preparation of oral health must be carried out, during, where one seeks to alleviate or minimize the consequences of treatment and after, where the quality of oral health is maintained, and the control of the sequelae resulting from the treatment is made [5]. Therefore, the present study aims to make a review on the management of these patients who have complications of head and neck radiotherapy.

\section{Radiation carie and xerostomia}

They are complications, with varying prevalence, from 20 to $70 \%$ depending on the type of study and are closely linked. Xerostomia causes functional problems in the oral cavity, affecting speech and taste, in addition to causing difficulties in chewing and swallowing. In addition, hyposalivation increases the risk of developing infections such as candidiasis, gingivitis, in addition to increasing the risk of radiation caries [4].

Systemic care to prevent xerostomia only occurs in research. The most appropriate conduct begins with good oral hygiene, which decreases the effect of dry mouth and its consequences. Salivary substitutes are used to relieve symptoms, such as artificial saliva and constant mucosal irrigation. sialogues like chewing gum are also used to stimulate salivary glands [6].

Radiation caries is a unique, rapidly progressing disease that can be seen within several months of starting treatment, is painless and affects teeth that are normally resistant to caries, such as incisors. They usually start in the cervical areas and progress through the entire crown of the tooth, leaving it fragile [7].

To act in the treatment of radiation caries, the dental surgeon must understand that he may face additional difficulties such as trismus and dental fragility itself, caused by the destruction of its structure [3].

Some studies indicate that alterations induced by radiation, in the enamel and dentin, can compromise the bonding of adhesive materials, although there is still no consensus [8]. Glass ionomer cements (GICs) enjoy simpler bonding procedures and good chemical adhesion, in addition to the release of fluoride, which can reduce recurrent caries. Some studies have pointed out the effectiveness of this material, showing significantly less recurrent caries, so they should be

${ }^{\star}$ Correspondence to: Igor Figueiredo Pereira. Universidade de Pernambuco Faculdade de Odontologia de Pernambuco. Hospital Universitário Oswaldo Cruz. R. Arnóbio Marquês, 310 - Santo Amaro, Recife - PE, 50100-130. Universidade de Pernambuco - PE, Brazil, E-mail: figueiredo.ctbmf@gmail.com

Key words: head and neck oncology, management, radiotherapy

Received: September 03, 2020; Accepted: October 06, 2020; Published: October 09,2020 
the material of choice for restorations, which can be conventional or resinous [9].

\section{Mucositis}

Oral mucositis is one of the most significant and prevalent complications of the treatment of HNC [10]. Pathogenesis is complex and is also related to xerostomia. It can occur during and after treatment, with effects that can vary from severe pain, difficulties in eating and performing oral hygiene, compromising quality of life and can even lead to suspension of cancer treatment, increasing the risk of death [11].

Mucositis may appear with erythema in its initial manifestation, followed by scaling white plaques, which can turn into ulcers, causing severe pain [12]. The most affected regions are the buccal floor, lateral border of the tongue, buccal mucosa and palate [13]. Difficulty in hygiene due to pain and lack of follow-up can worsen the condition [14].

Many interventions have been tried, which have some positive effects in the treatment of oral mucositis. Of which stand out: aloe vera, amphotericin antibiotic pastille / paste and sucralfate, laser and even cryotherapy, with ice application, that can cause some relief in symptoms [15].

The use of codeine can be useful as intermediate pain relievers. It is likely that the worsening of symptoms requires strong opioids such as morphine [5]. A study carried out in Brazil, using propolis gel, obtained excellent results, both in decreasing prevalence and in relieving symptoms of mucositis, but additional studies must be carried out to better support this evidence [16].

\section{Candidiasis}

Patients undergoing radiotherapy have a higher prevalence of oral candidiasis. It is an opportunistic infection, produced by fungi of the genus Candida (candida spp.) [17]. Oral candidiasis can be categorized into three types. Pseudomembranous oral candidiasis is characterized by the appearance of white moss, erythematous oral candidiasis by the eruption of erythema, and hyperplastic oral candidiasis by mucosal hyperplasia. Symptoms may be absent or include burning pain, difficulty swallowing, dysgeusia and halitosis. The diagnosis of oral candidiasis is fundamentally clinical, microbiological techniques are used when the clinical diagnosis needs to be confirmed and biopsies, in turn, are more indicated in patients with hyperplastic candidiasis [18].

Persistent candidiasis can be treated with antifungals. There is evidence to suggest that nystatin should not be used at the same time as chlorhexidine, as they may inhibit the action of the other. Should use occur, at least one hour apart [5]. Systemic ketoconazole may also be effective. Care with oral hygiene is also important in its prevention, as well as in the use of salivary substitutes, avoiding alcohol and smoking. Treatment may also include topical miconazole and fluconazole, available at. When systemic therapy, the first line medication is oral fluconazol [3].

\section{Osteorradionecrosis}

It is one of the most serious and important complications resulting from radiotherapy treatment, occurring mainly late. Initially, it appears as asymptomatic bone changes, such as decreased bone density, delayed healing and destruction of the cortical bone, in addition to ulcers and oral fistulas. Pain, stench and difficulty in chewing are also found [19].
Preventive measures are the best way to fight osteoradionecrosis. For this reason, the adequacy of the oral environment and the preparation of patients before the beginning of radiotherapy is essential, where teeth with problems and possible complications are removed. Broadspectrum prophylactic antibiotics also help prevent [5].

Hyperbaric oxygen is used to increase the blood-tissue oxygen gradient, which enhances the diffusion of oxygen into hypoxic tissues. The increase in oxygen supply stimulates fibroblast proliferation, angiogenesis and collagen formation. HBO therapy (HBOT) involves breathing oxygen under increased atmospheric pressure in a specially designed chambe [20]. Some studies indicate this method as effective in combating osteoradionecrosis.

More recent treatments indicate good results with the synergy between pentoxifylline (PTX) and tocopherol (vitamin E). Antioxidant agent PTX, facilitates microcirculation, and inhibits the inflammatory mechanisms, promotes fibroblast proliferation and the formation of extracellular matrix. Tocopherol protects the cell membrane against peroxidation. These are accessible, well tolerated and safe drugs [21].

\section{Conclusions}

Complications resulting from radiotherapy are varied and aggressive. There are several methods to prevent and treat these diseases. In many cases, they are just palliative therapies, to relieve pain and more serious symptoms. The main objective in the care of these patients is to maintain a good quality of life and support the continuation of therapy against cancer. Many patients have to abandon therapy if proper management is not carried out. Prevention and dental care before, during and after radiotherapy are essential for successful care with these patients.

\section{Acknowledgments}

The first author was granted a doctor's degree scholarship from the National Council for Scientific and Technological Development (CNPq), Ministry of Science and Technology, Brazil. The author Belmiro Cavalcanti do Egito Vasconcelos was granted from the National Council for Scientific and Technological Development (CNPq), Ministry of Science and Technology, Brazil. And the PFA / UPE-N04 / 2019 notice.

\section{Authorship}

Author IFP contributed in the planning, literature review and writing. BCdoEV contributed with critical review, read and approved the final manuscript.

\section{Conflict of interest}

$$
\text { No. }
$$

\section{References}

1. WHO (2010) International statistical classification of diseases and related health problems. (10th Edn), World Health Organization, Geneva.

2. Ray-Chaudhuri A, Shah K, Porter RJ (2013) The oral management of patients who have received radiotherapy to the head and neck region. Br Dent $J$ 214: 387-393. [Crossref]

3. Beech N, Robinson S, Porceddu S, Batstone M (2014) Dental management of patients irradiated for head and neck câncer. Aust Dent J 59: 20-28. [Crossref]

4. Porter SR, Fedele S, Habbab KM (2010) Xerostomia in head and neck malignancy Oral Oncol 46: 460-463. [Crossref]

5. H Jawad, NA Hodson, PJ Nixon. (2015) A review of dental treatment of head and neck cancer patients, before, during and after radiotherapy: part 2. Br Dent $J$ 218: 69-74. [Crossref] 
6. Kielbassa AM, Hinkelbein W, Hellwig E, Meyer-L€uckel H (2006) Radiation-related damage to dentition. Lancet Oncol 7: 326-335. [Crossref]

7. Springer IN, Niehoff P, Warnke PH, Bocek G, Kovacs G et al. (2005) Radiation caries — radiogenic destruction of dental collagen. Oral Oncol 41: 723-728. [Crossref]

8. CJ Soares, CG Castro, NA Neiva, PV Soares, PCF Santos-Filho, et al. (2010) Effect of gamma irradiation on ultimate tensile strength of enamel and dentin. J Dent Res 89: 159-164. [Crossref]

9. De Moor RJ, Stassen IG, van’t Veldt Y, Torbeyns D, Hommez GM (2011) Two-year clinical performance of glass ionomer and resin composite restorations in xerostomic head- and neck-irradiated cancer patients. Clin Oral Investig 15: 31-38. [Crossref]

10. Carneiro-Neto JN, de-Menezes JD, Moura LB, Massucato EM, de-Andrade CR (2017) Protocols for management of oral complications of chemotherapy and/or radiotherapy for oral cancer: Systematic review and meta-analysis current. Med Oral Patol Oral Cir Bucal 22: 15-23. [Crossref]

11. Mosel DD, Bauer RL, Lynch DP, Hwang ST (2011) Oral complications in the treatment of cancer patients. Oral Dis 17: 550-559. [Crossref]

12. Keefe DM, Schubert MM, Elting LS, Sonis ST, Epstein JB et al. (2007) Updated clinical practice guidelines for the prevention and treatment of mucositis. Cancer 109 820-831. [Crossref]

13. Moslemi D, Nokhandani AM, Otaghsaraei MT, Moghadamnia Y, Kazemi S et al (2016) Management of chemo/radiationinduced oral mucositis in patients with head and neck cancer: A review of the current literature. Radiother Oncol 120: 13-20. [Crossref]
14. Pereira IF, Firmino RT, Meira HC, DO Egito Vasconcelos BC, DE Souza Noronha VRA, et al. (2019) Radiation-induced Oral Mucositis in Brazilian Patients: Prevalence and Associated Factors. In Vivo 33: 605-609. [Crossref]

15. Worthington HV, Clarkson JE, Bryan G, Furness S, Glenny AM, et al. (2011) Interventions for preventing oral mucositis for patients with cancer receiving treatment. Cochrane Database Syst Rev 2011: CD000978. [Crossref]

16. Noronha VR, Araujo GS, Gomes RT, Iwanaga SH, Barbosa MC, et al. (2014) Mucoadhesive propolis gel for prevention of radiation-induced oral mucositis. Cur Clin Pharmacol 9: 359-364. [Crossref]

17. Gligorov J, Bastit L, Gervais H, Kahila W, Lepille D, et al. (2011) Prevalence and treatment management of oropharyngeal candidiasis in cancer patients: results of the French CANDIDOSCOPE study. Int J Radiat Oncol Biol Phys 80: 532-539. [Crossref]

18. Worthington HV, Clarkson JE, Khalid T, Meyer S, McCabe M (2007) Intervention for treating oral candidiasis for patients with cancer receiving treatment. Cochrane Database Syst Rev 18: CD001972. [Crossref]

19. Pereira IF, Firmino RT, Meira HC, Vasconcelos BC, Noronha VR, et al. (2018) Osteoradionecrosis prevalence and associated factors: A ten years retrospective study. Med Oral Patol Oral Cir Bucal 23: 633-638. [Crossref]

20. Jacobson AS, Buchbinder D, Hu K, Urken ML (2010) Paradigm shifts in the management of osteoradionecrosis of the mandible. Oral Oncol 46: 795-801. [Crossref]

21. Delanian S, Chatel C, Porcher R, Depondt J, Lefaix JL (2011) Complete restoration of refractory mandibular osteoradionecrosis by prolonged treatment with a pentoxifyllinetocopherolclodronate combination (PENTOCLO): a phase II trial. Int $J$ Radiat Oncol Biol Phys 80: 832-839. [Crossref]

Copyright: $(02020$ Pereira IF. This is an open-access article distributed under the terms of the Creative Commons Attribution License, which permits unrestricted use, distribution, and reproduction in any medium, provided the original author and source are credited. 